\section{THE LEFT VENTRICLE: TO RECONSTRUCT OR NOT- LESSONS FROM THE STICH TRIAL}

\section{To the Editor:}

Recently at the 89th Annual Meeting of The American Association for Thoracic Surgery in Boston, May 9-13, 2009 , there was a very clarifying debate on the STICH trial ${ }^{1}$ (Surgical Treatment for Ischemic Heart Failure) between Dr Robert H. Jones (pro) and Dr Gerald D. Buckberg (con), moderated by Dr Andrew S. Wechsler, which sparked the following thoughts.

Clearly, surgeons involved in the STICH trial had a difficult job: they were instructed to include patients in the trial if they honestly believed they could undergo coronary artery bypass grafting $(\mathrm{CABG})$ either alone or in combination with surgical ventricular reconstruction (SVR) with safety. It would seem likely that, ethically, patients with either global hypokinesis (no clear-cut aneurysm) or those with large aneurysms would be hard to include in this trial. Also, results of the two patient groups (CABG alone vs $\mathrm{CABG}+\mathrm{SVR}$ ) are uncannily similar: identical improvements in congestive heart failure and angina class for both groups (1.7 and 1.0, respectively), increase in distance on the 6-minute walk test ( 48 vs $52 \mathrm{~m}$ ), death or hospital readmission for cardiac cause (59\% vs $58 \%)$, death from any cause ( $28 \%$ vs $28 \%$ ), hospitalization for cardiac cause $(42 \%$ vs $41 \%$ ), and operative mortality as-

\footnotetext{
The Editor welcomes submissions for possible publication in the Letters to the Editor section that consist of commentary on an article published in the Journal or other relevant issues. Authors should: - Include no more than 500 words of text, three authors, and five references. - Type with double-spacing. - See http://jtcs.ctsnetjournals.org/misc/ifora.shtml for detailed submission instructions. - Submit the letter electronically via jtcvs.editorialmanager.com. Letters commenting on an article published in the JTCVS will be considered if they are received within 6 weeks of the time the article was published. Authors of the article being commented on will be given an opportunity of offer a timely response ( 2 weeks) to the letter. Authors of letters will be notified that the letter has been received. Unpublished letters cannot be returned.
}

treated $(5 \%$ vs $6 \%)$ or as intentionto-treat $(5 \%$ vs $5 \%)$. These results are practically identical as if coming from a single patient population divided in half....because they are. They were selected by ethical surgeons aware of the extensive current literature by many expert surgeonscientists working on hibernating myocardium (no aneurysm, poor ventricles) and overgrown ventricles resulting from infarction (aneurysm causing poor function). Perhaps during the conception of STICH such knowledge was not available, but perhaps the performance of SVR (or not) has reached the level of the "randomized controlled study of the parachute." The real message of the STICH trial is this: if one is pondering treatment of patients with poor ventricular function and mild aneurysmal dilatation, do not perform the SVR surgery, because if you do not send the patient to heaven, you will only prolong his or her and your own suffering (increased crossclamp, operative, and intensive care unit times and total length of stay) with no clinical benefit in ensuing years. The STICH investigators and surgeons are to be congratulated for their ethical dealing with this controversial topic. However, the message that $C A B G$ surgery alone is enough for patients with coronary artery disease and left ventricular aneurysms should not be interpreted from the STICH trial, as many patients with disabling left ventricular aneurysms would be at risk for the wrong treatment.

\section{Teresa Mary Kieser, MD, FRCSC, FACS \\ Department of Cardiac Sciences University of Calgary Calgary, Alberta, Canada}

\section{Reference}

1. Jones RH, Velazquez EJ, Michler RE, Sopko G, Oh JK, O'Connor CM, et al. Coronary bypass surgery with or without surgical ventricular reconstruction. N Engl J Med. 2009;3601-13.

doi:10.1016/j.jtcvs.2009.06.004

\section{CLARIFICATION OF STATEMENTS MADE REGARDING INVESTIGATION INTO AMPLATZER DEVICE COMPLICATION INCIDENCE AND COMPARISON WITH THE SOCIETY OF THORACIC SURGERY DATABASE \\ To the Editor:}

As the corresponding first author and presenter of the article regarding the Amplatzer device (AGA Medical Corporation, Plymouth, Minn) complications and comparison with the Society of Thoracic Surgery database, ${ }^{1}$ I must clarify some statements made regarding the work of previous authors on the complications of the Amplatzer device. $^{2}$ In formulating a calculation that was used to estimate complication frequency, we based our mathematics on estimates that were previously used by Amin and colleagues. ${ }^{2}$ Our point in noting that there was financial disclosure in the previous work was not to suggest that the data were not accurate. In fact, we were counting on the accuracy of these data because we also used the data for our calculation. Rather than questioning the work of these authors, we were in fact relying on the integrity of their estimates to make our own calculations. The authors most closely associated with this device serve as the best possible source of such information, and highlighting this relationship was only intended to add validity to our own calculation.

There was absolutely no intended implication of foul play or acting in conflict of interest in the case of these authors and indeed no such accusation was directly made. That some complications go unreported to the MAUDE database is most probably true but this has nothing to do with the work of Amin and colleagues, ${ }^{2}$ and these must be kept seperate in the readers' minds to understand the spirit of this work. The previous publications on the complications with Amplatzer devices were as accurate as any, and our addition to the literature presents the most up to date. That the frequency 